\title{
Voltage enhancement in dye-sensitized solar cell using (001)-oriented anatase $\mathrm{TiO}_{2}$ nanosheets
}

\author{
Barbora Laskova • Marketa Zukalova • \\ Ladislav Kavan • Alison Chou • Paul Liska • \\ Zhang Wei • Liu Bin • Pavel Kubat • Elham Ghadiri • \\ Jacques E. Moser • Michael Grätzel
}

Received: 13 November 2011 /Revised: 13 March 2012 / Accepted: 15 March 2012 /Published online: 11 April 2012

(C) The Author(s) 2012. This article is published with open access at Springerlink.com

\begin{abstract}
A nanocrystalline $\mathrm{TiO}_{2}$ (anatase) nanosheet exposing mainly the (001) crystal faces was tested as photoanode material in dye-sensitized solar cells. The nanosheets were prepared by hydrothermal growth in HF medium. Good-quality thin films were deposited on F-doped $\mathrm{SnO}_{2}$
\end{abstract}

B. Laskova $\cdot$ M. Zukalova $\cdot$ L. Kavan $(\bowtie) \cdot$ P. Kubat

J. Heyrovský Institute of Physical Chemistry, v.v.i.,

Academy of Sciences of the Czech Republic,

Dolejškova 3,

18223 Prague 8, Czech Republic

e-mail: kavan@jh-inst.cas.cz

B. Laskova $\cdot$ L. Kavan

Department of Inorganic Chemistry, Faculty of Science,

Charles University,

Hlavova 2030,

12843 Prague 2, Czech Republic

A. Chou

ARC Centre of Excellence for Functional Nanomaterials,

The University of Queensland,

Level 5, AIBN Building No. 75,

Corner College and Cooper Roads,

St Lucia, Queensland 4072, Australia

P. Liska $\cdot$ M. Grätzel

Laboratory of Photonics and Interfaces,

Institute of Chemical Sciences and Engineering,

Swiss Federal Institute of Technology,

1015 Lausanne, Switzerland

Z. Wei $\cdot$ L. Bin

Department of Chemical and Biomolecular Engineering,

National University of Singapore,

Singapore 117576, Singapore

E. Ghadiri · J. E. Moser

Photochemical Dynamics Group, Institute of Chemical Sciences

and Engineering, Swiss Federal Institute of Technology,

1015 Lausanne, Switzerland support from the $\mathrm{TiO}_{2}$ suspension in ethanolic or aqueous media. The anatase (001) face adsorbs a smaller amount of the used dye sensitizer (C101) per unit area than the (101) face which was tested as a reference. The corresponding solar cell with sensitized (001)-nanosheet photoanode exhibits a larger open-circuit voltage than the reference cell with (101)-terminated anatase nanocrystals. The voltage enhancement is attributed to the negative shift of flatband potential for the (001) face. This conclusion rationalizes earlier works on similar systems, and it indicates that careful control of experimental conditions is needed to extract the effect of band energetic on the current/voltage characteristics of dye-sensitized solar cell.

Keywords Titanium dioxide - Anatase .

Dye-sensitized solar cell

\section{Introduction}

Dye-sensitized solar cell (DSC), also called Grätzel cell, represents an attractive alternative of solid state photovoltaics due to high efficiency, low cost, and easy fabrication [1-4]. Optimization of $\mathrm{TiO}_{2}$ photoanode for dye-sensitized solar cell has been a subject of numerous studies, and nanocrystalline anatase turned out to be the best material for this device [5]. The voltage enhancement is crucial for further improvement of DSCs [1, 3, 6-10]. Promising data were acquired recently by replacing the traditional electrolyte redox relay, $\mathrm{I}_{3}{ }^{-} / \mathrm{I}^{-}$by other systems $[3,6-10]$, but little is known about the voltage enhancement via tuning of the photoanode material.

The (101) face is dominating in ordinary $\mathrm{TiO}_{2}$ (anatase) materials ( $>94 \%$ of the total surface area of crystals) [11]. The remaining face on the anatase crystal is (001) which is 
consistent with the conclusion that a truncated bipyramid is the corresponding crystal morphology [12]. Only rarely, the rhombic-shaped crystals are found, exposing the (010) face [13]. Both (001) and (010) facets are called "high-energy" or "reactive" ones, and they show interesting activity in catalysis and photocatalysis [13-16].

Comparative studies of anatase (101) or (001) faces have been carried out on macroscopic single-crystal electrodes $[17,18]$, but the dye sensitization was attempted only on the (101) face of the single-crystal electrode [17]. The works on single-crystal electrodes confirmed that the (001) face had more negative flatband potential and was more active for $\mathrm{Li}$ insertion than the (101) face [18]. The conclusion about flatband potential shift was later reproduced on polycrystalline electrodes [19]. Also, the improved Li insertion was subsequently confirmed on polycrystalline (001)-oriented nanosheets [20]. They were prepared hydrothermally in HF medium according to Yang et al. [11], and the follow-up studies [14, 15, 21-23] report on materials enriched up to $90 \%$ with the (001) face.

Recently, Wang et al. [24] studied the sensitization of such (001) nanosheets by CdS quantum dots, but no comparison with (101)-exposing crystals was presented. This was carried out earlier by $\mathrm{Yu}$ et al. [25], who observed improved conversion efficiency of a DSC employing hydrothermally grown nanosheets sensitized by the organometallic dye, N719 [chemical name: di-tetrabutylammonium cisbis(isothiocyanato)bis(2,2'-bipyridyl-4,4' dicarboxylato) ruthenium(II)], as the photoanode material. They attributed the improvement to three effects specific for the (001)-oriented nanosheets: (1) enhanced diffusion of the electrolyte, (2) more easy adsorption of the dye, and (3) fewer defects in the surface. However, there were no clear experimental data about electrolyte diffusion and defects, and the amount of adsorbed dye (N719) was actually smaller on nanosheets than that on nanoparticles [25] which seems to contradict the statement (2). Yang et al. [23] reported recently on hierarchical spheres with over $90 \%$ (001) faces which were more active than the Degussa P25 titania material in dyesensitized solar cells, and the effect was ascribed to (1) stronger ability to dissociatively "absorb" $(\mathrm{COOH})$ groups, (2) higher surface area for dye loading, (3) light scattering, and (4) smaller electron losses at grain interfaces [23]. However, these conclusions were not supported by direct experimental data. Zhang et al. [26] tested the (001)-exposed microspheres in a bilayer photoanode with Degussa P25 underlayer, and concluded that the beneficial effect consists in enhanced light scattering on the mirror-like (001) facets.

To address these divergences, we report here on a comparative study showing that a significant effect favoring the (001) nanosheets is the enhanced open-circuit voltage of the solar cell. This result is consistent with the negative shift of flatband potential of the (001) face. To the best of our knowledge, this conclusion is presented here for the first time; hence, it upgrades earlier works dealing with these problems $[23,25,26]$.

\section{Experimental section}

\section{Materials}

Anatase $\mathrm{TiO}_{2}$ nanosheets were prepared as follows: $10 \mathrm{~mL}$ of titanium (IV) butoxide was mixed with $0.8-1.2 \mathrm{~mL}$ of hydrofluoric acid (concentration, $\approx 50 \%$ ). The mixture was sealed in a Teflon cell encased in a stainless steel autoclave and heated at $180-200{ }^{\circ} \mathrm{C}$ for $24 \mathrm{~h}$. A sample was then collected, washed with copious amounts of Milli-Q water and finally dried at $100{ }^{\circ} \mathrm{C}$. The reference material was prepared in the same way, but in the absence of HF which was replaced by the same amount of water. X-ray diffraction patterns (data not shown) confirmed that the reference material was phase-pure anatase. For comparison, a second reference material (coded C240) [27] was also used. It is nanocrystalline anatase, $S_{\mathrm{BET}}=89 \mathrm{~m}^{2} / \mathrm{g}$, prepared by hydrolysis of titanium tetra(isopropoxide) and hydrothermal recrystallization at $240{ }^{\circ} \mathrm{C}$ in the absence of HF [28]. The crystal morphology of $\mathrm{C} 240$ is characterized by particles ca. $10-20 \mathrm{~nm}$ in size exposing mainly the (101) facets, and it is frequently used for DSC [29]. The photoelectrochemical behavior of both reference materials was very similar.

Electrodes from all parent powder materials (see above) were fabricated using either aqueous paste (A films) or simply ethanolic suspension (E films). The aqueous paste was prepared as follows: $0.3 \mathrm{~g}$ of the powder was mixed under slow addition of $4 \times 0.15 \mathrm{~mL}$ of $10 \%$ aqueous solution of acetylacetone, $0.3 \mathrm{~mL}$ of $4 \%$ aqueous solution of hydroxypropylcellulose (MW 100,000), and $0.3 \mathrm{~mL}$ of $10 \%$ aqueous solution of Triton-X100. The obtained slurry was deposited on F-doped $\mathrm{SnO}_{2}$ (FTO) glass (TEC 15 from Libbey-Owens-Ford, $15 \Omega / \mathrm{sq}$ ) with Kapton foil tape defining the $\mathrm{TiO}_{2}$ film edges. The film was then calcined for $30 \mathrm{~min}$ in air at $450{ }^{\circ} \mathrm{C}$. For the preparation of $\mathrm{E}$ film electrodes, the powder samples were sonicated in ethanol. The obtained slurry was deposited by doctor blading, and a uniform semitransparent film was obtained after drying at room temperature and calcination in air at $450{ }^{\circ} \mathrm{C}$. Typical film thickness was 2-4 $\mu \mathrm{m}$ (Alpha-step profilometer, Tencor Instruments) for both $\mathrm{A} / \mathrm{E}$ films.

The C101 dye $\left[\mathrm{NaRu}\left(4,4^{\prime}\right.\right.$-bis(5-hexylthiophene-2-yl)2,2'-bipyridine)(4-carboxylic acid-4'-carboxylate-2,2'bipyridine)(NCS $)_{2}$ ] with chenodeoxycholic acid (cheno) as a coadsorbent was used for sensitization (see [30] for details). Immediately after calcination, the still warm electrode (ca. $50{ }^{\circ} \mathrm{C}$ ) was dipped in a solution containing 
$300 \mu \mathrm{mol} / \mathrm{L}$ of $\mathrm{C} 101$ dye and $300 \mu \mathrm{mol} / \mathrm{L}$ cheno in a mixed solvent of acetonitrile $+\mathrm{t}$-butanol solution $(1: 1, v / v)$. The electrodes were soaked at room temperature in the solution overnight to secure complete attachment of the sensitizer dye to the electrode surface. To avoid irregularities in dye attachment [31], the sensitization time and temperature were identical for all the tested electrodes. The DSC was assembled with platinized F-doped tin oxide (FTO) counter electrode $[32,33]$ using a Surlyn tape $(25 \mu \mathrm{m}$ in thickness $)$ as a seal and spacer. The electrolyte solution was $0.6 \mathrm{M} \mathrm{N}$ methyl- $N$-butyl imidazolium iodide, $40 \mathrm{mM} \mathrm{I}_{2}, 0.075 \mathrm{M}$ lithium iodide, $0.26 \mathrm{M}$ tert-butylpyridine, and $0.05 \mathrm{M}$ guanidine thiocyanate in acetonitrile/valeronitrile $(85 / 15 \%, v / v)$. The cell active area for illumination was $0.22 \mathrm{~cm}^{2}$, defined by a mask.

\section{Methods}

The X-ray diffraction (XRD) was investigated on powder samples by XRD-6000, Shimadzu, Japan, using Ni-filtered $\mathrm{CuK} \alpha$ radiation $(\lambda=0.15418 \mathrm{~nm})$. The transmission electron microscopy (TEM) images were measured on a JEOL JEM2010F microscope. The BET surface areas of the prepared powder materials were determined from nitrogen adsorption isotherms at $77 \mathrm{~K}$ using the Micromeritics ASAP 2020 instrument. The surface areas of thin films were determined from $\mathrm{Kr}$-adsorption isotherms, which were measured directly on the sintered films following the methodology described in [34]. The surface concentration of the $\mathrm{C} 101$ dye on $\mathrm{TiO}_{2}$ was measured spectrophotometrically as follows: The sensitized electrode was dipped in $0.1 \mathrm{M}$ tetrabutylammonium hydroxide in dimethylformamide and stirred until complete desorption into the liquid took place. The solution was analyzed on the PerkinElmer Lambda 1050 spectrometer using the extinction coefficient $\varepsilon_{550}=17.5 \cdot 10^{3} \mathrm{M}^{-1} \mathrm{~cm}^{-1}$ [30]. The dye surface coverage $\left(\Gamma_{\text {dye }}\right)$ was determined by normalizing the found dye concentration to the film's physical surface area from $\mathrm{Kr}$ adsorption isotherm. Scanning electron microscopy (SEM) and energy-dispersive X-ray analysis (EDX) were carried out with the Hitachi FE SEM S-4800 microscope equipped with the Noran EDX system. Electrochemical measurements were carried out in a one-compartment cell using an Autolab Pgstat-30 (Ecochemie) controlled by GPES-4 software. For photoelectrochemical tests, the light source was a $450-\mathrm{W}$ xenon light source (Osram XBO 450, Germany) with a filter (Schott 113). The light power was regulated to the AM 1.5G solar standard by using a reference $\mathrm{Si}$ photodiode equipped with a color-matched filter (KG-3, Schott) to reduce the mismatch in the region of $350-750 \mathrm{~nm}$ between the simulated light and AM $1.5 \mathrm{G}$ to less than $4 \%$. The differing intensities were regulated with a neutral wire mesh attenuator. The applied potential and cell current were measured using a
Keithley model 2400 digital source meter. Optical determination of the flatband potential was made by a spectroelectrochemical method described in [35-37]. The measurement was carried out in $0.2 \mathrm{M} \mathrm{NaClO}_{4}$ (pH adjusted by $\mathrm{HClO}_{4}$ or $\mathrm{NaOH}$ ) using UV-vis-NIR spectrometer PerkinElmer Lambda 1050 interfaced to a potentiostat. Measurements were performed in transmission mode at gradually decreasing potentials from $0 \mathrm{~V}$ to -1.2 or $-1.4 \mathrm{~V}$. Potential was set, and after $1.5 \mathrm{~min}$ at the given potential, the spectrum was measured. For data processing, the measured spectra were normalized by subtracting the spectrum measured at $0 \mathrm{~V}$. Nanosecond flash photolysis was applied to C101 dyesensitized transparent $\mathrm{TiO}_{2}$ layers covered by a film of pure methoxypropionitrile and a thin cover glass. Pulsed excitation $(\lambda=530 \mathrm{~nm}, 5-\mathrm{ns}$ FWHM pulse duration, $20-\mathrm{Hz}$ repetition rate) was provided by an optical parametric oscillator (GWU OPO-355), pumped by a frequency-tripled, Q-switched Nd: YAG laser (Continuum, Powerlite 7030). The laser beam output was expanded by plano-concave lens to irradiate a large cross section of the sample, whose surface was kept at a $30^{\circ}$ angle to the excitation beam. The probe light, produced by a Xe arc lamp, passed through the first monochromator, various optics, and the sample. Transmitted light was focused on the entrance slit of the second monochromator and detected by a fast photomultiplier tube. Data waves were recorded on a DSA 602A digital signal analyzer (Tektronix). Satisfactory signal-to-noise ratios were typically obtained by averaging over 3,000 laser shots.

\section{Results and discussion}

Figure 1a shows a typical X-ray diffraction pattern of $\mathrm{TiO}_{2}$ nanosheets (grown in HF medium), indicating the formation of pure anatase $\mathrm{TiO}_{2}$ (JCPDS no. 21-1272). The diffractograms of (001) nanosheets are similar to those of (101)nanoparticles, which is in accord with earlier literature [11, $14,15,21,22]$. As XRD is obviously not very sensitive to distinguish the (001) or (101) oriented anatase crystals, the morphology of our $\mathrm{TiO}_{2}$ anatase nanosheets was characterized by transmission electron microscopy. A typical nanosheet dimension was $40 \cdot 30 \cdot 7 \mathrm{~nm}^{3}$ (Fig. 1b). Figure 1c shows a high-magnification TEM image of two selected individual $\mathrm{TiO}_{2}$ nanosheets (ca. $30 \cdot 20 \cdot 7 \mathrm{~nm}^{3}$ in size). The lattice spacing parallel to the top and bottom facets was determined to be $\sim 0.235 \mathrm{~nm}$, corresponding to the (001) planes of anatase $\mathrm{TiO}_{2}$. Figure $1 \mathrm{~d}$ shows the corresponding selected-area electron diffraction (SAED) pattern (indexed as the (001) zone axis diffraction). It further indicates that the top and bottom facets of the nanosheets are the (001) planes. The anatase nanosheets exhibited a specific surface area from nitrogen adsorption measurement, $S_{\mathrm{BET}}$ between 85 and $120 \mathrm{~m}^{2} / \mathrm{g}$ depending on the sample batch. Higher values were 
Fig. 1 Structural

characteristics of (001) nanosheets. a XRD pattern. b Low-magnification TEM image. c High-magnification TEM image. d Typical

SAED pattern of an individual $\mathrm{TiO}_{2}$ nanosheet

\section{a}

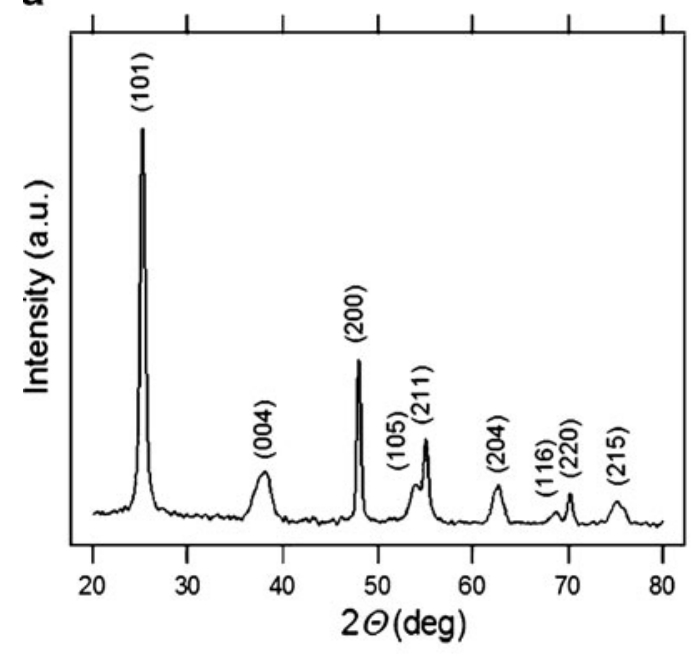

C

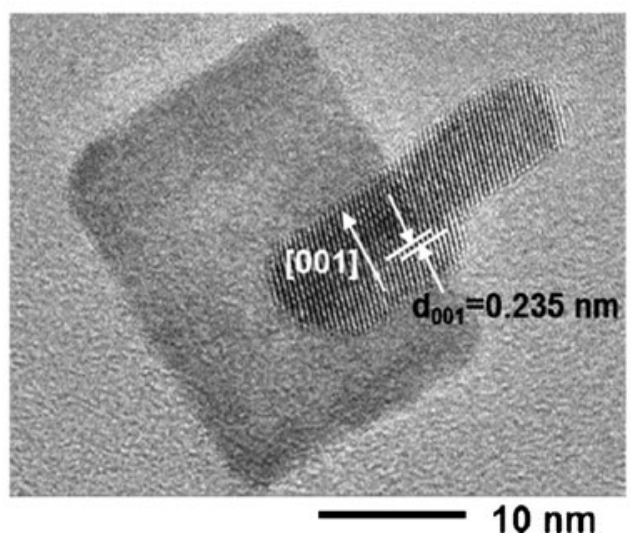

b

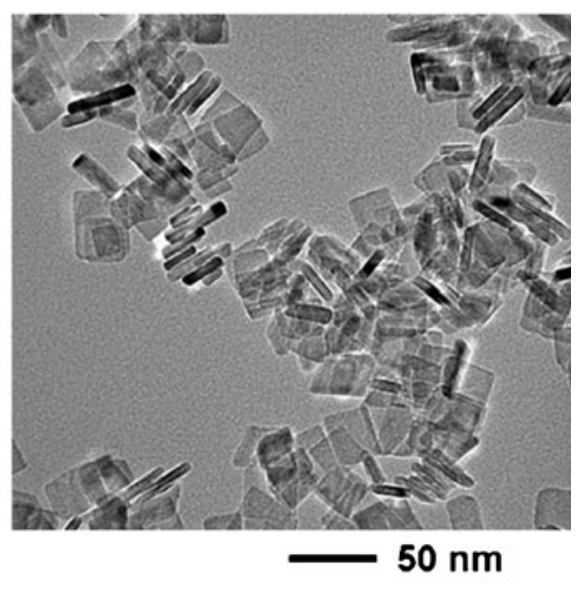

d

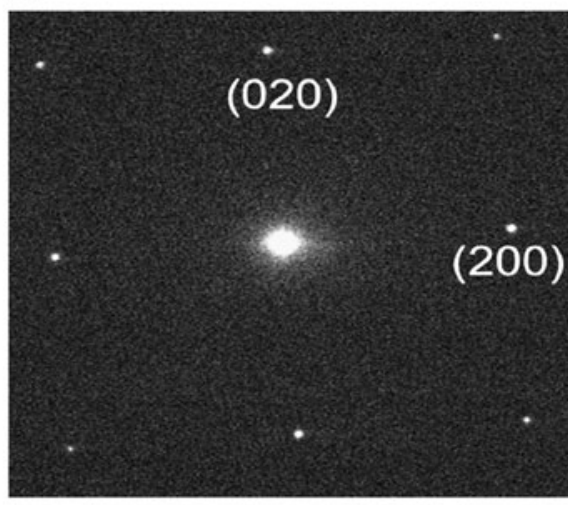

observed in products grown from mixtures containing less $\mathrm{HF}$ and autoclaved at lower temperatures (see "Experimental section"). The typical nanosheet dimension of $40 \cdot 30 \cdot 7 \mathrm{~nm}^{3}$ (cf. Fig. 1b) translates into the calculated $S_{\text {BET }}$ of $103 \mathrm{~m}^{2} / \mathrm{g}$, which matches reasonably well the experimental values from adsorption isotherms. The particles grown in HF-free medium had $S_{\mathrm{BET}}=150 \mathrm{~m}^{2} / \mathrm{g}$ and exhibited the usual bipyramidal crystal shape with (101) facets. This morphology resembles that of C240 particles optimized earlier for DSC applications [29].

SEM images of our nanosheet-based electrodes are shown in Fig. 2. Both variants of $\mathrm{TiO}_{2}$ film deposition (A films, E films; see "Experimental section") exhibited a similar morphology of unorganized nanoplatelets which were reasonably uniform and non-agglomerated. This is beneficial for achieving good optical and mechanical quality of the films. It should be noted that even the E films were optically semitransparent with good adhesion to the FTO support in spite of the very simple deposition procedure used and the fact that particles were not stabilized against agglomeration by any other additives as in the case of A films (see "Experimental section"). The as-received nanosheet material contained $8 \mathrm{wt} \%$ of $\mathrm{F}$, as determined by EDX analysis, but the heat treatment during electrode fabrication $\left(450{ }^{\circ} \mathrm{C}, 30 \mathrm{~min}\right.$; see "Experimental section) caused the $\mathrm{F}$ content to drop practically to zero for both the A and E films.

The actual surface area of electrodes (determined from the Kr-adsorption isotherm of the thin-film samples) was normalized to the projected geometric area, which provided the roughness factor. The found values of roughness factor were from 100 to 600 for various film thicknesses, but without significant distinction between the A and $\mathrm{E}$ films. More importantly, the surface concentration of the dye $\left(\Gamma_{\text {dye }}\right)$ was, for both film types $(\mathrm{A}, \mathrm{E})$, significantly smaller on the (001) films compared to that on (101) films (Table 1). The found $\Gamma_{\text {dye }}$ for (101) films is comparable to the values reported earlier for various Ru-bipyridine sensitizers adsorbed on titania (from 0.56 to 1.16 molecules $/ \mathrm{nm}^{2}$; see [38] for the data overview). Recently, Sauvage et al. [31] studied the $\mathrm{C} 101$ dye adsorption on $\mathrm{TiO}_{2}$ film which was, obviously, rich in the (101)-terminated anatase particles. They found an almost perfect dye monolayer (assuming $\Gamma_{\text {dye }}=0.57$ molecules $/ \mathrm{nm}^{2}$ ) only for the films sensitized at low temperature $\left(4^{\circ} \mathrm{C}\right)$, but the dye coverage exceeded the 
Fig. 2 Scanning electron microscopy images of the FTO-deposited film from (001)-oriented nanosheets. Left: A film, right: E film
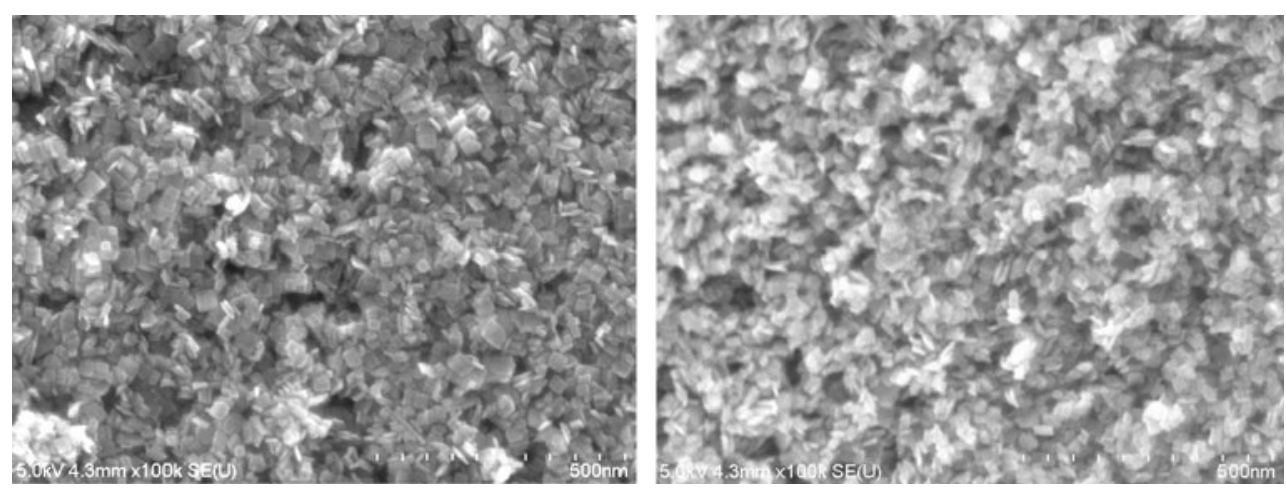

monolayer saturation limit for the films sensitized at room or higher temperatures. In accord with this report, both our (101) films adsorb more C101 dye than expected for a monolayer (Table 1). However, our $\Gamma_{\text {dye }}$ values for the (001) films are below this limit. The relatively smaller dye loading on the (001) face was also reported for the N719 dye [25], but the reason for smaller adsorption capacity of this face is unclear. The anchoring of N719 and N3 dyes [N3 is cis-bis(isothiocyanato) bis(2,2'-bipyridyl-4,4'-dicarboxylato ruthenium(II)] on the (101) face was investigated carefully, including quantum chemical simulations [38, 39], but there is no corresponding study of the (001) face nor that of other dyes like $\mathrm{C} 101$.

The trend that smaller values of $\Gamma_{\text {dye }}$ are observed for the (001) films qualitatively agrees with the conclusion of Yu at al. [25] who reported that the surface concentration of N719 dye was $143 \mathrm{nmol} / \mathrm{cm}^{2}$ for the (001) nanosheets or $214 \mathrm{nmol} / \mathrm{cm}^{2}$ for the reference (101) nanoparticles, respectively. However, the values reported by Yu et al. [25] do not seem to be normalized to the physical (BET) area of the $\mathrm{TiO}_{2}$ film as in our case. (Note that the recalculated $\Gamma_{\text {dye }}$ for the physical surface area would be unrealistically high in the cited work [25], ca. a thousand molecules per square nanometer). Also, we should note that our data in Table 1 do not support the assumption of Yang et al. [23] that the (001) face has better ability to adsorb the N719 dye.

Figure 3 shows the current-voltage characteristics of a solar cell employing the dye-sensitized A films (Fig. 3a) and
E films (Fig. 3b). In both cases, data are plotted for (001)oriented nanosheets (full curves) and reference (101) particles (dashed curves). For the reference (101) particles, we report on the materials grown from Ti(IV) butoxide in HFfree medium $\left(S_{\mathrm{BET}}=150 \mathrm{~m}^{2} / \mathrm{g}\right)$, but the plots for our second (101) reference $\left(\mathrm{C} 240, S_{\mathrm{BET}}=89 \mathrm{~m}^{2} / \mathrm{g}\right)$ were quite similar (data not shown). Detailed results about our solar cells are collected in Table 1. It is obvious that the (001)-oriented nanosheet films exhibit smaller short-circuit photocurrents $\left(I_{\mathrm{sc}}\right)$, particularly at $100 \%$ sun illumination, when the light harvesting is less efficient, and also, the $\Gamma_{\text {dye }}$ concentrations are lower (Table 1). Hence, we attribute the smaller $I_{\mathrm{sc}}$ to smaller dye loading on the (001) nanosheets. At $10 \%$ sun, the differences in photocurrents are less pronounced or even negligible (A film, Fig. 3a). The (101) particles in A film further show superlinear response to light intensity which might be caused by some dye aggregation. This effect, albeit less pronounced, is also expressed for the remaining films in Table 1. It is further illustrated by higher $\eta$ values for higher light intensity. Usually, we observe opposite trends [30], but there are also examples when $\eta$ and light intensity do not scale monotonically for dyes of this type [40]. Furthermore, there is no proportionality between the efficiency, $\eta$, and $\Gamma_{\text {dye }}$ (Table 1). This finding is supported by Sauvage et al. [31] who reported on decreasing efficiency for the C101sensitized films, if the $\Gamma_{\text {dye }}$ was larger than the monolayer coverage. They concluded that subtle structural characteristics at the $\mathrm{C} 101 / \mathrm{TiO}_{2}$ interface influence the

Table 1 Characteristics of dye-sensitized solar cells with various $\mathrm{TiO}_{2}$ films

\begin{tabular}{|c|c|c|c|c|c|c|c|c|c|}
\hline \multirow[t]{2}{*}{ Film type } & \multirow[t]{2}{*}{$\Gamma_{\text {dye }}\left[\right.$ molecules $\left./ \mathrm{nm}^{2}\right]$} & \multicolumn{4}{|l|}{$10 \%$ sun } & \multicolumn{4}{|l|}{$100 \%$ sun } \\
\hline & & $I_{\mathrm{sc}}\left[\mathrm{mA} / \mathrm{cm}^{2}\right]$ & $U_{\mathrm{oc}}[\mathrm{mV}]$ & $\mathrm{FF}$ & $\eta[\%]$ & $I_{\mathrm{sc}}\left[\mathrm{mA} / \mathrm{cm}^{2}\right]$ & $U_{\mathrm{oc}}[\mathrm{mV}]$ & $\mathrm{FF}$ & $\eta[\%]$ \\
\hline A-(001) & 0.4 & 0.86 & 620 & 0.74 & 4.2 & 8.78 & 708 & 0.69 & 4.3 \\
\hline A-(101) & 0.7 & 0.89 & 566 & 0.73 & 3.8 & 10.4 & 660 & 0.69 & 4.7 \\
\hline E-(001) & 0.5 & 0.51 & 625 & 0.74 & 2.5 & 5.34 & 725 & 0.72 & 2.8 \\
\hline E-(101) & 0.8 & 0.65 & 583 & 0.72 & 2.8 & 6.36 & 681 & 0.71 & 3.1 \\
\hline
\end{tabular}

$\Gamma_{d y e}$ surface concentration of the $\mathrm{C} 101$ dye in molecules per square nanometer, $I_{s c}$ short-circuit photocurrent, $U_{o c}$ open-circuit voltage, $F F$ fill factor, $\eta$ solar conversion efficiency 
Fig. 3 Current-voltage characteristics of dye-sensitized solar cells employing C101-sensitized $\mathrm{TiO}_{2}$ photoanode either from (001)-oriented nanosheets (solid red lines) or reference (101) nanoparticles (dashed blue lines). a A films, b E films
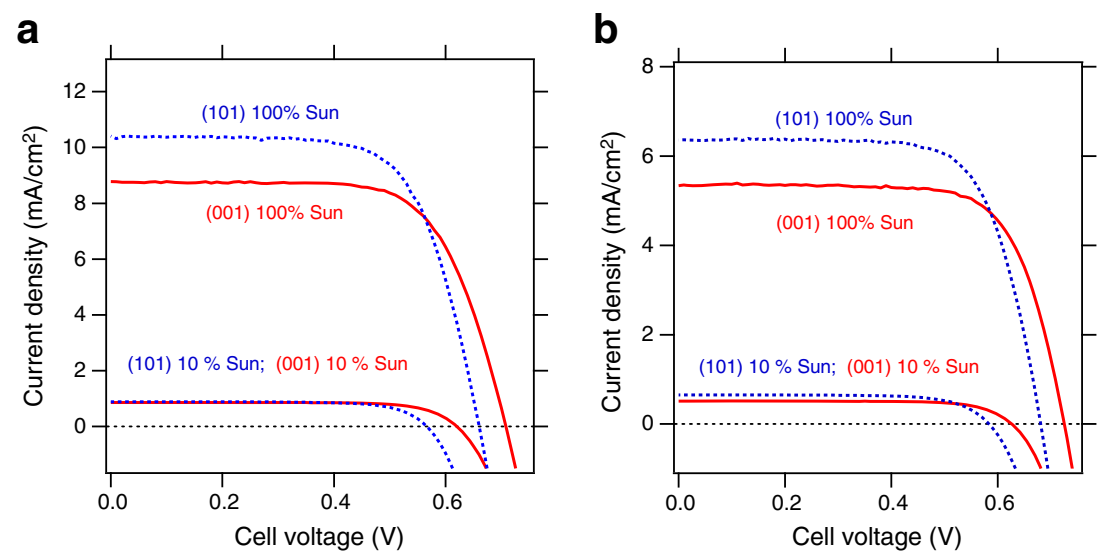

electron transfer dynamics and light harvesting of the assembly [31].

The actually measured photocurrent is further dependent on the $\mathrm{TiO}_{2}$ film thickness. This is difficult to control accurately in various film-deposition techniques; hence, the matching of photocurrents in Fig. 3 a (10\% sun) is casual only. From this point of view, we should consider with care the conclusion by $\mathrm{Yu}$ at al. [25] who observed a larger photocurrent for the (001) nanosheets, compared to that for (101) nanoparticles and reference commercial titania (P25, Degussa). They reported a film thickness of "about $10 \mu \mathrm{m}$," but the surface concentration of the used dye (N719) was actually smaller by a factor of ca. 1.5 on the (001) nanosheets compared to that on their reference (101) nanoparticles [25]. The relatively smaller dye loading for (001) nanosheets compared to that on (101) particles was also reproduced by us (see $\Gamma_{\text {dye }}$ values in Table 1). At full sun illumination, our solar conversion efficiencies $\eta$ are slightly better for the (101)-terminated nanocrystals. This is due to the dominating contribution of enhanced photocurrent for this face. Our conclusion is in conflict with Yu et al. [25] who reported just the opposite trend in photocurrents and $\eta$ values.

Figure 3 and Table 1 demonstrate that the most pronounced effect distinguishing (001) nanosheets from the ordinary (101) nanoparticles is the open-circuit voltage $\left(U_{\mathrm{oc}}\right)$ enhancement of the former. The found differences in open-circuit voltage between nanosheets and nanoparticles $\left(\Delta U_{\text {oc }}\right.$ ) were 54 or $48 \mathrm{mV}$ (for A films at 10 or $100 \%$ sun, respectively) and 42 or $44 \mathrm{mV}$ for $\mathrm{E}$ films at the corresponding conditions and for the actual experiments demonstrated in Table 1. It should be noted that these numbers (and the data in Fig. 3 and Table 1) represent only a single set of measurements; hence, experimental errors and the likely sample-tosample variations could be unnoticed. To avoid such mistakes, we have carried out a statistical evaluation of data using an array of parallel tests on various $\mathrm{TiO}_{2}$ films with a different preparation history. This analysis showed statistically insignificant differences between $\mathrm{A}$ and $\mathrm{E}$ films. The averaged values for both film types (A, E) were as follows:

$\Delta U_{\mathrm{oc}}=(47 \pm 3) \mathrm{mV}$ at $10 \%$ sun illumination

$\Delta U_{\mathrm{oc}}=(45 \pm 2) \mathrm{mV}$ at $100 \%$ sun illumination

Obviously, even the dependence on the light intensity is not very pronounced too. This points at the hypothesis, that $\Delta U_{\mathrm{oc}}$ reflects a fundamental physical effect (albeit small) but not a variable introduced by experimental conditions, such as film thickness, preparation history, dye loading, light intensity, etc. More specifically, one of the reasons for positive values of $\Delta U_{\mathrm{oc}}$ can be the corresponding shift of flatband potential of (001) faces/(101) faces.

Similarly enhanced voltage $\left(\Delta U_{\mathrm{oc}}=20 \mathrm{mV}\right)$ was found for 001-terminated anatase in hierarchical spheres, referred to the value for P25 particles [23]. However, the enhancement was not discussed in [23] and we should also note that P25 is hardly the optimum reference material. It is, actually, a mixture of anatase and rutile, while both phases exhibit a significantly different electronic structure: e.g., the flatband potential of rutile is by $0.2 \mathrm{~V}$ more positive than the value for anatase [17].

In contrast to these data, Yu et al. [25] reported on negligible differences in $U_{\text {oc }}$ for their (001) nanosheets, (101) nanoparticles, and the P25 film sensitized by N719. To address this paradox, we should note that $\mathrm{Yu}$ et al. [25] found a considerably smaller $U_{\text {oc }}$ (ca. 580 to $590 \mathrm{mV}$ at $100 \%$ sun) for their DSCs compared to our values (Table 1). Smaller $U_{\text {oc }}$ values may stem from a voltage drop caused by enhanced recombination of photoinjected electrons in the titania conduction band with the electrolyte [4, 41], and this effect can mask any other mechanism of fine tuning of $U_{\mathrm{oc}}$, e.g., by crystal face orientation.

Our combination of cheno-coadsorbent with highextinction dye (C101) provides, obviously, a more-defined interface for exploring small $U_{\mathrm{oc}}$ shifts undisturbed by such parasitic effects. Cheno improves the dye attachment by assembling the geometry of the surface complex, prevents 
agglomeration of dye molecules, and decreases the recombination losses with the electrolyte solution [30, 42, 43]. Furthermore, the back electron transfer can be hindered by a compact titania underlayer on top of the FTO support [4]. This strategy is unsuitable for our study, aiming at the distinction of (001)- and (101)-terminated nanocrystals, but we should note that the optimization of the morphology of $\mathrm{TiO}_{2}$ photoanode may further enhance $U_{\text {oc }}$ for a DSC device quite similar to ours [30]. Hence, the elimination of all the other factors influencing $\Delta U_{\mathrm{oc}}$ is essential, if subtle effects caused by band energetic are to be unraveled.

To test our hypothesis about different band energetic, Fig. 4 compares spectroelectrochemical data for thin-film electrodes made from (001)- and (101)-terminated nanocrystals. This technique was developed for determination of the flatband potential of transparent semiconductors, and it is particularly useful for nanocrystalline electrodes where the standard method based on electrochemical impedance (Mott-Schottky plots) is complicated by various factors [35-37]. The flatband potential of anatase, $E_{\mathrm{fb}}$ (in volts) is known to exhibit Nernstian dependence on $\mathrm{pH}$ :

$E_{\mathrm{fb}}=E_{0}-0.0591 \mathrm{pH}$

where the constant $E_{0}$ was reported to be $-0.4 \mathrm{~V}$ for the (101) face assuming a saturated calomel electrode (SCE) as the reference electrode $[17,35,36]$. The negative shift of absorbance/potential profiles for the (001)-oriented film is apparent from Fig. 4, although the absorbance onset potential is not that clearly different. This might be due to surface states which contribute differently in (001) or (101) films. Based on optical spectra and X-ray photoelectron spectroscopy (XPS), Pan et al. [16] concluded that the conduction band edge of (001) face is upshifted (in electrochemical scale) by $0.04 \mathrm{~V}$. This

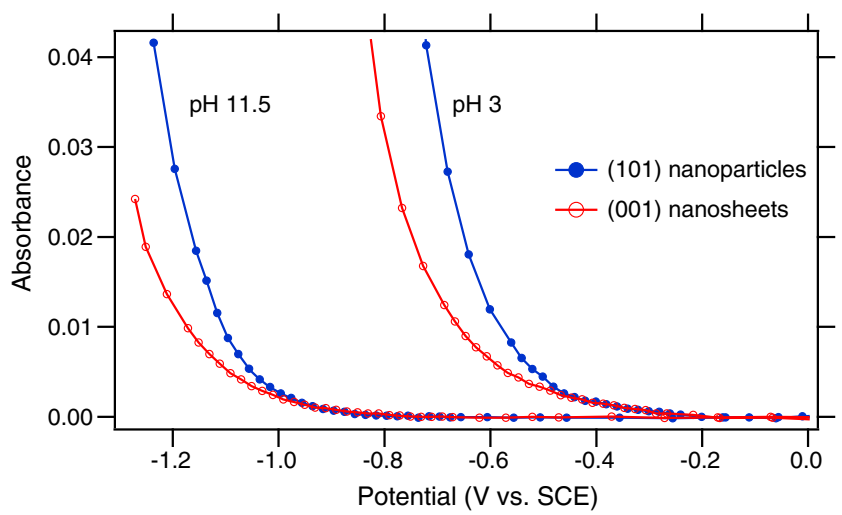

Fig. 4 Optical absorbance of $\mathrm{TiO}_{2}$ films from (001)- or (101)-oriented nanosheets plotted by open red points or full blue points, respectively. The absorbance was measured at $640 \mathrm{~nm}$ and normalized to the mass of the $\mathrm{TiO}_{2}$ film. It is plotted as a function of the applied electrochemical potential in $0.2 \mathrm{M} \mathrm{NaClO}_{4}$ at two different $\mathrm{pH}$ values. The lines are guides to the eye contradicts our conclusion, as well as earlier spectroelectrochemical reports on single-crystal [18] and polycrystalline [19] electrodes. (One of the reasons for this discrepancy might be that the reported upshift is within experimental error of the determination of the valence band edge by XPS [16].)

Our data are in qualitative accord with the earlier conclusion by Kawakita et al. [19] based on Mott-Schottky plots for (001)- vs. (101)-oriented nanocrystals similar to ours. These authors reported on negative shift of $E_{\mathrm{fb}}$ for their (001)-oriented nanocrystals; the $E_{\mathrm{fb}}$ values were from ca. -0.4 to $0 \mathrm{~V}$ vs. SCE for various samples at $\mathrm{pH} 6$ (phosphate buffer). This is more positive than the value of $E_{\mathrm{fb}} \approx-0.75 \mathrm{~V}$ predicted by Eq. (1), but the difference was not commented on in [19]. As discussed above, accurate impedance data are available for single-crystal electrodes only; in this case, the $E_{\mathrm{fb}}$ values for (001) face were negatively shifted by $0.06 \mathrm{~V}$ compared to that of (101) face [18]. This negative shift of $E_{\mathrm{fb}}$ is not far from the observed enhancement of opencircuit voltage, $\Delta U_{\text {oc }}$ of ca. $0.04 \mathrm{~V}$ found in this study (vide ultra). However, there might be also other effects at play, such as different geometry of the dye/titania surface complex [44].

To get further insight into the specific behavior of (001) nanosheets referenced to that of (101) nanoparticles, we employed transient absorption spectroscopy. Nanosecond flash excitation was applied to $\mathrm{C} 101$-sensitized $\mathrm{TiO}_{2}$ film contacting pure methoxypropionitrile solvent. Monitoring the transient absorbance signal at a wavelength $\lambda=650 \mathrm{~nm}$ allowed to follow the time course of the dye cation $\mathrm{S}^{+}$ produced upon ultrafast electron injection from the photoexcited sensitizer, $\mathrm{S}^{*}$, into the conduction band of $\mathrm{TiO}_{2}$ (Eq. 2). In the absence of electrolyte (redox mediator), the

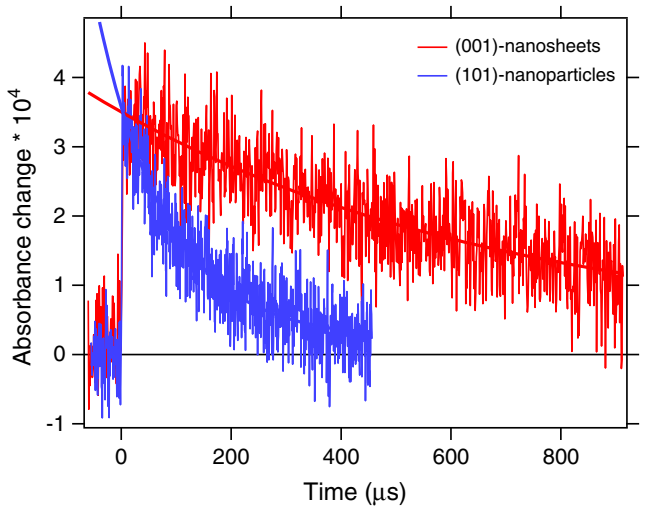

Fig. 5 Temporal behavior of the transient absorbance measured at $\lambda=$ $650 \mathrm{~nm}$ for a C101 dye-sensitized anatase (001)-nanosheet film, covered by pure methoxypropionitrile solvent, upon ns-pulsed laser excitation (red trace). A typical transient absorbance decay curve obtained in identical conditions with (101) nanoparticles is shown for comparison (blue trace). Amplitudes of both signals were normalized at time zero for a better visual comparison. The first-order kinetic fits are indicated on top of each experimental curve 
decay of the $\mathrm{S}^{+}$signal was due to the back electron transfer reaction (Eq. 3).

$$
\begin{aligned}
& \mathrm{S}\left|\mathrm{TiO}_{2}+\mathrm{h} v \rightarrow \mathrm{S}^{*}\right| \mathrm{TiO}_{2} \rightarrow \mathrm{S}^{+}+\mathrm{e}^{-} \mathrm{cb}\left(\mathrm{TiO}_{2}\right) \\
& \mathrm{S}^{+}+\mathrm{e}^{-}{ }_{\mathrm{cb}}\left(\mathrm{TiO}_{2}\right) \rightarrow \mathrm{S} \mid \mathrm{TiO}_{2}
\end{aligned}
$$

The excitation pulse fluence was progressively decreased by neutral density filters until the signal displayed a single exponential decay (Fig. 5). The used fluence of $35 \mu \mathrm{J} / \mathrm{cm}^{2}$ was then believed to relate to the injection of at most one electron per $\mathrm{TiO}_{2}$ nanoparticle or nanosheet. The transport of charges between individual nanoparticles or nanosheets is negligible within the sub-millisecond time frame of the back electron transfer process.

The corresponding rate constant, $k_{\mathrm{b}}$ (Eq. 3), can be obtained from first-order kinetic fit of the absorbance change, $\triangle A$ :

$$
\Delta A=C+B \cdot \exp \left(-k_{\mathrm{b}} \cdot t\right)
$$

where $t$ is time and $C$ and $B$ are constants. The fitted values of $k_{\mathrm{b}}$ are: $1.2 \cdot 10^{3} \mathrm{~s}^{-1}$ for the (001) nanosheets and $7.7 \cdot 10^{3} \mathrm{~s}^{-1}$ for the (101) nanoparticles, respectively. Hence, the back electron transfer is by a factor of 6 slower for the (001) nanosheets compared to the same process on (101) nanoparticles. The difference in the back electron transfer kinetics observed for both samples could be rationalized by a change in the dye-anchoring geometry. Assuming a damping coefficient $\beta=1.2 \AA^{-1}$ for through-space electron tunneling (Eq. 5), retardation of the charge recombination reaction by a factor of 6 corresponds to the increase of the electron transfer distance existing between the Ru(III) center of the oxidized dye and the closest Ti(IV) site on the surface of the oxide by $\Delta r=1.5 \AA$ :

$k_{\mathrm{b}}=k_{b}^{0} \cdot \exp (-\beta \Delta r)$

$\mathrm{C} 101$ has only two carboxylic anchoring groups available on a single bpy ligand. The distance between the $\mathrm{Ru}$ ion and the $\mathrm{TiO}_{2}$ thus depends strongly upon the tilt angle of the pyridyl rings on the surface. Because the dicarboxylated bpy ligand (bi-isonicotinic acid) tends to distort upon anchoring on the $\mathrm{TiO}_{2}$ surface, different geometries are expected on the (101) and (001) surfaces [45]. The distance between the Ru center of the dye and the $\mathrm{Ti}^{4+}$ ion directly linked to one of the oxygen atoms of the carboxylic anchor is $\approx 10 \AA$ when the bpy adopts a flat structure. A change of the tilt angle of the pyridyl rings related to the surface normal of ca. $15^{\circ}$ on the (001) facet to ca. $35^{\circ}$ on the (101) facet would yield a decrease of the distance between the Ru center in the dye to the surface:

$$
\Delta r=10 \cdot \cos 15-10 \cdot \cos 35 \approx 1.5 \AA
$$

which is the $\Delta r$ value calculated from our experimental data (Eq. 5).
In DSCs, the back electron transfer process competes kinetically with the regeneration of the dye by the donor species of the electrolyte. As the latter reaction should not depend upon the crystalline face on which the dye is adsorbed, the retardation of the back electron transfer can only improve the charge separation yield. The difference in back electron transfer rate $\left(k_{\mathrm{b}}\right)$ hardly influences the opencircuit voltage of the cell. The $U_{\mathrm{OC}}$ certainly depends on the injected electrons' quasi-Fermi level [2, 4]. However, the electrons' lifetime is controlled by the competition between their transport in the $\mathrm{TiO}_{2}$ network and their recombination with the oxidized mediator $\left(\mathrm{I}_{3}{ }^{-}\right)$. The recombination between conduction-band electrons and the dye cations, $\mathrm{S}^{+}$, is generally sufficiently intercepted by the reduction of $\mathrm{S}^{+}$ by $\mathrm{I}^{-}$and is not expected to influence the potential of DSC.

\section{Conclusion}

Nanocrystalline $\mathrm{TiO}_{2}$ (anatase) in two different crystal morphologies exposing mainly the (001) or (101) crystal faces was employed as a photoanode material in dye-sensitized solar cells. The (001) face adsorbs a smaller amount of the used dye sensitizer (C101) but provides a larger open-circuit voltage of the solar cell. The negative shift of flatband potential is suggested to be responsible for the observed enhancement of $U_{\text {oc }}$. This conclusion helps to rationalize contradictory data in the earlier literature. Furthermore, it indicates that careful control of experimental conditions is needed to extract the effect of band energetic on the current/ voltage characteristics of the dye-sensitized solar cell.

Acknowledgments This work was supported by the Academy of Sciences of the Czech Republic (contracts IAA 400400804 and KAN 200100801), Grant Agency of the Czech Republic (contract no. P108/ 12/0814), and the EC 7th FP project SANS (contract no. NMP246124). B.L. thanks the National Research Foundation of Singapore (R279-000-276-272) for financial support. M.G. is very grateful to the European Research Council (ERC) for supporting his research under the ERC-2009-AdG grant no 247404 MESOLIGHT.

Open Access This article is distributed under the terms of the Creative Commons Attribution License which permits any use, distribution, and reproduction in any medium, provided the original author(s) and the source are credited.

\section{References}

1. Grätzel M (2001) Nature 414:338-344

2. Hagfeldt A, Boschloo G, Sun L, Kloo L, Pettersson H (2010) Chem Rev 110:6595-6663

3. Yella A, Lee HW, Tsao HN, Yi C, Chandiran AK, Nazeeruddin MK, Diau EWG, Yeh CY, Zakeeruddin SM, Grätzel M (2011) Science 334:629-634

4. Kalyanasundaram K (2010) Dye sensitized solar cells. EPFL Press \& CRC Press, Lausanne 
5. Kavan L (2012) Chem Rec 12:131-142

6. Wang M, Chamberland N, Breau L, Moser J, Humphry-Baker R, Marsan B, Zakeeruddin SM, Grätzel M (2010) Nature Chem 2:385-389

7. Daeneke T, Kwon TH, Holmes AB, Duffy NW, Bach U, Spiccia L (2011) Nature Chem 3:211-215

8. Feldt SM, Gibson EA, Gabrielsson E, Sun L, Boschloo G, Hagfeldt A (2010) J Am Chem Soc 132:16714-16724

9. Kavan L, Yum JH, Grätzel M (2011) Nano Lett 11:5501-5506

10. Kavan L, Yum JH, Nazeeruddin MK, Grätzel M (2011) ACS Nano 5:9171-9178

11. Yang HG, Sun CH, Qiao SZ, Zou J, Liu G, Smith SC, Cheng HM, Lu GQ (2008) Nature 453:638-642

12. Olson CL, Nelson J, Islam MS (2006) J Phys Chem B 110:999510001

13. Wu B, Guo C, Zheng N, Xie Z, Stucky GD (2008) J Am Chem Soc 130:17563-17567

14. Han X, Kuang Q, Jin M, Xie Z, Zheng L (2009) J Am Chem Soc 131:3152-3153

15. Zhang D, Li G, Yang X, Yu JC (2009) Chem Commun 2009:4381-4383

16. Pan J, Liu G, Lu GQ, Cheng HM (2011) Angew Chem Int Ed 50:2133-2137

17. Kavan L, Grätzel M, Gilbert SE, Klemenz C, Scheel HJ (1996) J Am Chem Soc 118:6716-6723

18. Hengerer R, Kavan L, Krtil P, Grätzel M (2000) J Electrochem Soc $147: 1467-1472$

19. Kawakita M, Kawakita J, Sakka Y, Shinohara T (2010) J Electrochem Soc 157:H65-H68

20. Bousa M, Laskova B, Zukalova M, Prochazka J, Chou A, Kavan L (2010) J Electrochem Soc 157:A1108-A1112

21. Chen JS, Lou XW (2009) Electrochem Commun 11:2332-2335

22. Yang HG, Liu G, Qiao SZ, Sun CH, Jin YG, Smith SC, Zou J, Cheng HM, Lu GQ (2009) J Am Chem Soc 131:4078-4083

23. Yang W, Li J, Wang Y, Zhu F, Shi W, Wan F, Xu D (2011) Chem Commun 47:1809-1811

24. Wang X, Liu G, Wang L, Pan J, Lu GQ, Cheng HM (2011) J Mater Chem 21:869-873

25. Yu J, Fan J, Lv K (2010) Nanoscale 2:2144-2149

26. Zhang H, Han Y, Liu X, Yu H, Zhang S, Yao X, Zhao Z (2010) Chem Commun 46:8395-8397
27. Kavan L, Grätzel M, Rathousky J, Zukal A (1996) J Electrochem Soc 143:394-400

28. Barbe C, Arendse F, Comte P, Jirousek M, Lenzmann F, Shklover V, Grätzel M (1997) J Amer Ceram Soc 80:3157-3171

29. Grätzel M (2006) Prog Photovolt Res Appl 14:429-442

30. Gao F, Wang Y, Shi D, Zhang J, Wang M, Jing X, Humphry-Baker R, Wang P, Zakeeruddin SM, Grätzel M (2008) J Am Chem Soc 130:10720-10728

31. Sauvage F, Decoppet JD, Zhang M, Zakeeruddin SM, Comte P, Nazeeruddin MK, Wang P, Grätzel M (2011) J Am Chem Soc 133:9304-9309

32. Papageorgiou N, Maier WE, Grätzel M (1997) J Electrochem Soc $144: 876-884$

33. Murakami TN, Ito S, Wang Q, Nazeeruddin MK, Bessho T, Cesar I, Liska P, Humphry-Baker R, Comte P, Pechy P, Grätzel M (2006) J Electrochem Soc 153:A2255-A2261

34. Zukalova M, Zukal A, Kavan L, Nazeeruddin MK, Liska P, Grätzel M (2005) Nano Lett 5:1789-1792

35. Rothenberger G, Fitzmaurice D, Grätzel M (1992) J Phys Chem 96:5983-5986

36. Redmond G, Fitzmaurice D (1993) J Phys Chem 97:1426-1430

37. Kavan L, Stoto T, Grätzel M, Fitzmaurice D, Shklover V (1993) J Phys Chem 97:9493-9498

38. Zukalova M, Prochazka J, Zukal A, Yum JH, Kavan L (2008) Inorg Chim Acta 361:656-662

39. Fantacci S, De Angelis F (2011) Coord Chem Rev 2704-2726

40. Yu Q, Wang Y, Yi Z, Zu N, Zhang J, Zhang M, Wang P (2010) ACS Nano 4:6032-6038

41. Nazeeruddin MK, Kay A, Rodicio I, Humphry-Baker R, Mueller E, Liska P, Vlachopolous N, Grätzel M (1993) J Am Chem Soc 115:6382-6390

42. Morandeira A, Durante IL, O'Regan B, Martinez-Diaz MV, Fornelli A, Palomares E, Torres T, Durrant JR (2010) J Mater Chem 19:50165026

43. Yum JH, Jang SR, Humphry-Baker R, Grätzel M, Cid JJ, Torres T, Nazeeruddin MK (2008) Langmuir 24:5636-5640

44. De Angelis F, Fantacci S, Selloni A, Grätzel M, Nazeeruddin MK (2007) Nano Lett 7:3189-3195

45. Thomas AG, Flavell WR, Chatwin C, Rayner S, Tsoutsou D, Kumarasinghe AR, Brete D, Johal TK, Patel S, Purton J (2005) Surf Sci 592:159-168 